\title{
Production of Aluminum Glass Fiber Reinforced Foam Synthesized by Space-Holder Technique
}

\author{
A.T. ERTÜRK* \\ Kocaeli University, Ford Otosan Ihsaniye Vocational School of Automotive, Kocaeli, Turkey
}

\begin{abstract}
Aluminum and its reinforced type with glass fiber composite foams were produced by powder sintering process using spherical carbamide particles as a space holder. The foams with 40-60 vol.\% porosity fractions were successfully produced after water leaching and sintering methods. Compression test was performed on both of the foam samples for comparing the compressive properties and energy absorption behavior of them. The composite foam samples with glass fiber reinforcement showed higher compressive strength than the parent material foam.
\end{abstract}

DOI: 10.12693/APhysPolA.129.592

PACS/topics: 81.05.Rm, 81.05.Bx, 83.80.Ab, 81.20.Ev, 81.70.Bt

\section{Introduction}

Various special abilities such as high strength to weight ratios, excellent impact energy absorption, high specific stiffness make metal foams very attractive material for use in the automotive, aerospace, railway, and biomedical industries [1, 2]. Plenty of methods have been used to produce metal foams (e.g. $\mathrm{Al}, \mathrm{Ni}, \mathrm{Mg}$ and their alloys). These methods include solid, gas and liquid state processing. Among current manufacturing techniques, metal foams can be produced inexpensively by using an appropriate space-holder. The properties of metal foam depend on morphological features, such as cell wall curvature, pore size, shape and distribution etc. [3-5]. In order to make the production process more reliable and reproducible, the use of space-holder materials in powder metallurgy (PM) processing route is being widely used for its capability to produce fairly uniform metal foams, and commercially cost-effective compared with the other methods [6, 7]. Usually sodium chloride $(\mathrm{NaCl})$, carbamide, carbonate particles and also several polymers are used as extractable space-holder materials for manufacturing metal foams via powder sintering process $[7,8]$. It was reported that depending on the shape distribution of carbamide particles, morphology of pores in production can be controlled [9, 10]. Bafti and Habibolahzadeh [9] stated that carbamide was completely removed from the green compacts by water leaching at room temperature, without any distortion in compacts. Bekoz and Oktay [11] studied effects of carbamide shape and content on processing and properties of steel foams. The results indicated that increasing carbamide content and the use of spherical particles promoted carbamide removal in the water leaching step. Also, graded aluminum foams have recently been fabricated by Hassani et al. [12] concluded carbamide spacer was more feasible than $\mathrm{NaCl}$ spacer in producing density graded foam. An alternative

\footnotetext{
*e-mail: tamer.erturk@kocaeli.edu.tr
}

manufacturing method via the powder metallurgy is sintering and dissolution process (SDP) developed by Zhao and Sun [13]. The major drawback is aluminum foams made by SDP shows lower mechanical properties and eliminating the space holder is a time consuming stage.

In this article, production of aluminum glass fiber reinforcement foam (GFRF) using a space-holder method has been experienced. Spherical carbamide particles were used as space holder. Molecular formula of the carbamide is $\mathrm{H}_{2} \mathrm{NOCNH}_{2}$. The article aims to evaluate the production of reinforced type foams and the effect of glass fiber (GF) content on water leaching stage. Additionally, the compressive properties and the energy absorption behavior of the produced foams have been studied.

\section{Materials and method}

The aluminum powder used for the present study was gas-atomized (supplied by Gurel Makina) where its particle size was in the range of $30-50 \mu \mathrm{m}$, with a mean diameter of $45 \mu \mathrm{m}$ and with analyzed chemistry of $95.7 \mathrm{Al}$, $3.26 \mathrm{Si}, 0.41 \mathrm{Fe}, 0.21 \mathrm{Mg}, 0.02 \mathrm{Mn}, 0.12 \mathrm{Ti}, 0.09 \mathrm{Cu}$ (wt\% content). Commercial spherical shape carbamide $\left(\mathrm{CH}_{4} \mathrm{~N}_{2} \mathrm{O}\right)$ particles were used as a space-holder material. Particles were divided by a series of sieves to $1-2 \mathrm{~mm}$ size. The carbamide has a density of $1.32 \mathrm{~g} \mathrm{~cm}^{-3}$, melting temperature of $133^{\circ} \mathrm{C}$, and solubility in ethanol $\left(\right.$ at $20^{\circ} \mathrm{C}$ ) equal to $50 \mathrm{~g} / \mathrm{L}$. Glass-fiber (E-glass) was used in the mixing stage of production as the reinforcement. The diameters of the fibers were $15-20 \mu \mathrm{m}$ and the lengths were $6 \mathrm{~mm}$. The percentage of glass fiber was 1 and $3 \%$ by weight. The typical morphologies and blending of the raw materials are shown in Fig. 1a-d.

The production stages consisted of mixing, compacting, removing carbamide, and sintering. A schematic illustration of the production stages is shown in Fig. 2. The weight ratios of the aluminum powder, carbamide and glass fibers $(1.3 \mathrm{wt} \%)$ were calculated to obtain defined porosities of 40-60 vol.\% in sintered compact. Raw materials were mixed together in a rotary mixer for $1 \mathrm{~h}$. A small amount of ethanol (2 vol.\%) was sprayed on carbamide before blending to avoid segregation of the 

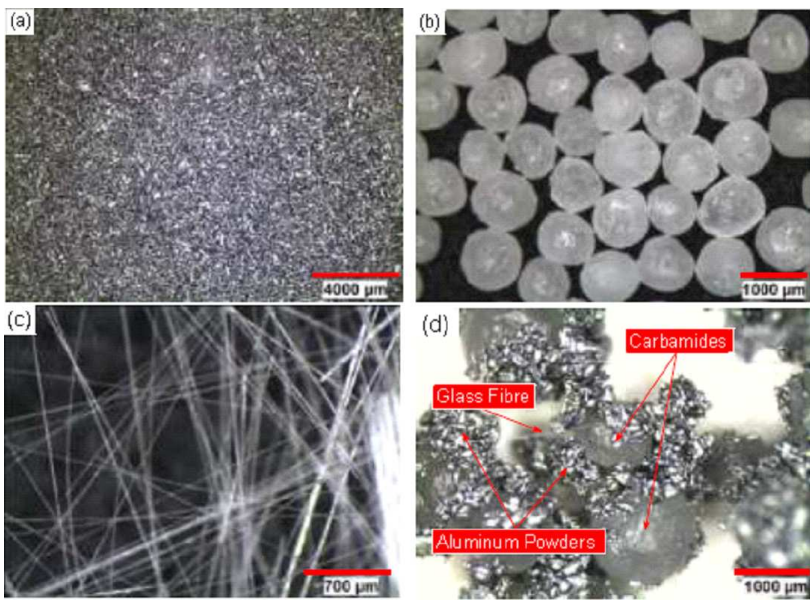

Fig. 1. Raw materials:

(a) aluminum powders, (b) spherical carbamide particles, (c) glass fibers, (d) blending.

dissimilar powders, and also to improve the strength of the green samples. The mixture was uniaxially compacted using a double action die $(d=22 \mathrm{~mm}, h=$ $20 \mathrm{~mm}$ ) with different pressures at 300 and $400 \mathrm{MPa}$ into cylindrical compacts.

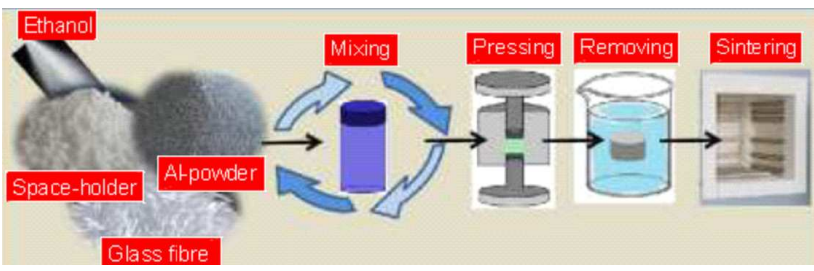

Fig. 2. Schematic illustration of the production stages.

Space-holder in the green compact was removed in water $\left(80^{\circ} \mathrm{C}\right)$ at regular intervals and weighed to determine the leaching proportion, dehydrated in a vacuum furnace $\left(P=10^{-4} \mathrm{~Pa}\right)$ at $50^{\circ} \mathrm{C}$ for $2 \mathrm{~h}$. After termination of the removal stage, the compacts were sintered at different temperatures $\left(600\right.$ and $\left.615^{\circ} \mathrm{C}\right)$ in a vacuum furnace $\left(P=10^{-4} \mathrm{~Pa}\right)$ for $2 \mathrm{~h}$. Sintering was performed under two conditions of solid-state $\left(600^{\circ} \mathrm{C}\right)$ and liquidstate $\left(615^{\circ} \mathrm{C}\right)$ sintering. The compacts were cooled in the furnace after sintering. The macro- and microstructure of the foams were examined by Nikon MA 100 optical microscope, Nikon SMZ-745T trinocular model stereo microscope and FEI Quanta 50 SEM/EDS equipment. The compression tests of the specimens were performed with DARTEC universal tensile testing equipment at a crosshead speed of $1 \mathrm{~mm} \mathrm{~min}^{-1}$.

\section{Results and discussion}

Figure $3 \mathrm{a}$ and $\mathrm{b}$ shows the pore forms resulting with different pressures at 300 and $400 \mathrm{MPa}$, respectively. The pores of foams with lower compaction (300 MPa) have a homogeneous and more uniform structure, which replicate perfectly the physical dimensions of carbamide particles. But some of the pore structure obtained with higher compaction (400 MPa) shows elliptical shape because of initial form changing of the some carbamide particles in the cross-section parallel to the compacting direction. Thus, it was concluded that compacting should be performed at $300 \mathrm{MPa}$ to obtain more spherical pores.

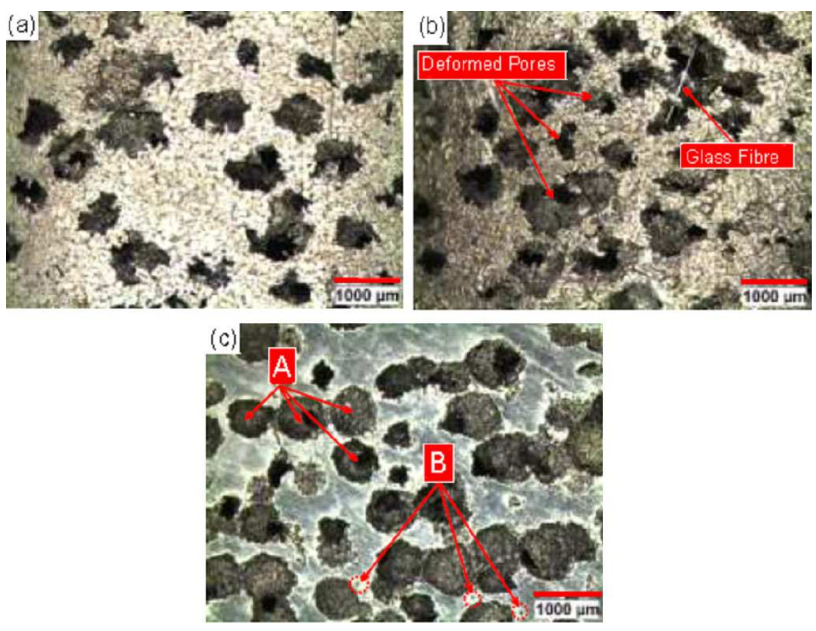

Fig. 3. Optical photographs of the pores (a) lower compaction, (b) higher compaction, (c) sintered structure of the pores.

The pore size (spherical diameter) and shape (sphericity) of the foams were determined using Clemex Vision image analysis software, given in Table I. Typically two types of pore structure were observed. The first type was macropores indexed A in Fig. 3c as a resultant of space holder material. The other one was micropore structure indexed as B in Fig. 3c, especially resulting in large numbers after solid-stage sintering on a cell wall. It can be concluded that formation amount of micropores is highly affected by sintering temperature. SEM micrographs in Fig. 4a and b reveal that liquid-state sintering provides better wetting between aluminum and fibers. The energy absorption behavior of GFRFs rely on the wetting ability and Al-GF bounding.
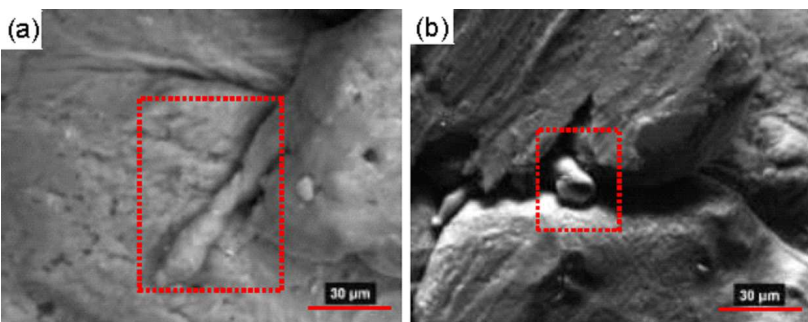

Fig. 4. SEM microstructure of cell wall after (a) liquidstate and (b) solid-state sintering.

The density of the green foam was calculated by dividing the mass by its volume. The dimensions were measured for volume calculation. After the sintering stage, porosities of the foam materials were calculated by using the following formula $[9,14]$ : 


$$
\text { porosity }=\left[1-\left(\frac{\rho_{\mathrm{f}}}{\rho_{\mathrm{Al}}}\right)\right] 100,
$$

where $\rho_{\mathrm{f}}$ and $\rho_{\mathrm{Al}}$ are densities of foam and bulk aluminum (2.75 $\mathrm{g} \mathrm{cm}^{-3}$ for aluminum powder), respectively.

Figure 5 shows the timely variation of removing carbamide within the aluminum foam and GFRFs (1-3 wt\%) in water leaching stage at $80^{\circ} \mathrm{C}$. Inceptive rates of all removing carbamide curves were higher due to the direct contact between water and carbamide surface. It can be seen that the slope of curves decreased with time because of decreasing contact surface. Similar results had been obtained previously in aluminum [9] and stainless steel [15] foams. As seen in Fig. 5, the total removing time of carbamide within the plain aluminum foam structure was $135 \mathrm{~min}$. This period resulted in the same time as $120 \mathrm{~min}$ for GFRFs (1 and $3 \mathrm{wt} \%$ ). Aluminum 60 vol.\% carbamide reinforced with 3 wt\% GF foam showed an exceptional time as the minimum removing period for $105 \mathrm{~min}$.

TABLE I

Structure of the produced foams: porosity, size, shape.

\begin{tabular}{|c|c|c|c|c|c|c|}
\hline \multirow[b]{2}{*}{ Foam sample } & \multirow{2}{*}{$\begin{array}{c}\text { Relative } \\
\text { density } \\
\left(\rho_{\mathrm{f}} / \rho_{\mathrm{Al}}\right)\end{array}$} & \multirow[b]{2}{*}{$\begin{array}{c}\text { Porosity } \\
{[\%]}\end{array}$} & \multicolumn{2}{|c|}{ Spherical diameter $[\mu \mathrm{m}]$} & \multicolumn{2}{|c|}{ Sphericity } \\
\hline & & & Mean & $\begin{array}{l}\text { Standard } \\
\text { deviation }\end{array}$ & Mean & $\begin{array}{l}\text { Standard } \\
\text { deviation }\end{array}$ \\
\hline Al-60 carbamide- $3 \mathrm{GF}$ & 0.3796 & 62.04 & 1081.7 & 121.2 & 0.54 & 0.186 \\
\hline Al-60 carbamide- $1 \mathrm{GF}$ & 0.3919 & 60.81 & 1321.2 & 158.5 & 0.58 & 0.147 \\
\hline Al-40 carbamide- $3 \mathrm{GF}$ & 0.5904 & 40.96 & 1115.4 & 164.6 & 0.61 & 0.166 \\
\hline Al-40 carbamide- $1 \mathrm{GF}$ & 0.5915 & 40.85 & 1049.5 & 156.4 & 0.65 & 0.131 \\
\hline Al-60 carbamide & 0.3857 & 61.43 & 994.3 & 147.6 & 0.54 & 0.124 \\
\hline Al-40 carbamide & 0.5984 & 40.16 & 1065.7 & 146.5 & 0.67 & 0.115 \\
\hline
\end{tabular}

TABLE II

Mechanical behavior of the produced foams.

\begin{tabular}{c|c|c|c|c|c|c}
\hline \hline \multirow{2}{*}{ Foam sample } & \multicolumn{2}{|c|}{$\begin{array}{c}\text { Elastic modulus } \\
{[\mathrm{GPa}]}\end{array}$} & \multicolumn{2}{|c|}{$\begin{array}{c}\text { Average plateau stress } \\
{[\mathrm{MPa}]}\end{array}$} & \multicolumn{2}{|c}{$\begin{array}{c}\text { Energy absorbtion } \\
{\left[\mathrm{MJ} \mathrm{m}^{-3}\right]}\end{array}$} \\
\cline { 2 - 7 } & L-state & S-state & L-state & S-state & L-state & S-state \\
\hline Al-60 carbamide-3 GF & 0.86 & 0.76 & 3.37 & 2.85 & 1.57 & 1.33 \\
Al-60 carbamide-1 GF & 0.91 & 0.82 & 3.30 & 2.73 & 1.52 & 1.26 \\
Al-40 carbamide-3 GF & 0.85 & 0.70 & 2.98 & 2.68 & 1.37 & 1.23 \\
Al-40 carbamide-1 GF & 0.86 & 0.73 & 3.09 & 2.69 & 1.49 & 1.30 \\
Al-60 carbamide & 0.85 & 0.77 & 2.71 & 2.46 & 1.22 & 1.11 \\
Al-40 carbamide & 0.77 & 0.65 & 2.64 & 2.21 & 1.19 & 1.00
\end{tabular}

Compression tests were performed uniaxially by loading along the directions parallel to the compacting directions on obtained sizes of the foams, taking into account ASTM E9-09 standard. Compressive force-stroke curves are shown in Fig. 6a and b. All the curves are compatible to previous studies $[5,7-9,12,14]$ with characteristic regions, i.e. linear elastic deformation, collapse plateau and densification region. The energy absorption capacity of an obtained foam was calculated from area under the compressive curve in the range of its plateau region $[8,9,12,14]$ :

$$
W=\int_{0}^{\varepsilon} \sigma \mathrm{d} \varepsilon .
$$

The elastic modulus of the produced foams was determined from the slope of the corresponding force-stroke graphs at $1 \%$ strain. The test results of the produced foams were given in Table II. The values of elastic modulus vary in the range from 0.65 to $0.91 \mathrm{GPa}$. Plateau stress was considered as the average stress in the range of 0 to $17 \mathrm{~mm}$ stroke $[9,12,14]$. As can be seen from Fig. 6a, after liquid state sintering GFRF with the lowest porosity of 40 vol. $\%$ and 3 wt $\%$ glass fiber content showed the highest strength of $5.91 \mathrm{MPa}$. Also the application of liquid-stage sintering improves the compression and energy absorption properties of the GFRFs. This indicates that strong interfacial bonds of aluminum/glass fiber formed on liquid-state sintering at $615{ }^{\circ} \mathrm{C}$. The solid-state sintered foam samples show brittle characteristic with irregular compression curves because of comprising microporosities. Microporosities could act as initial cracks. The results showed that the 


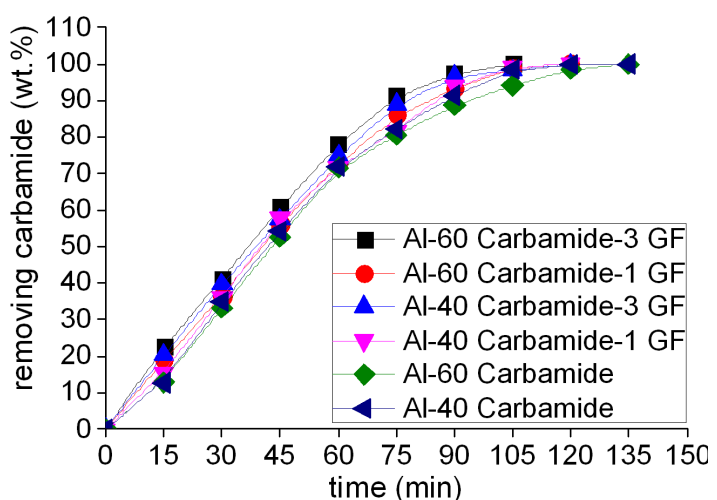

Fig. 5. Timely variation of removing carbamide.

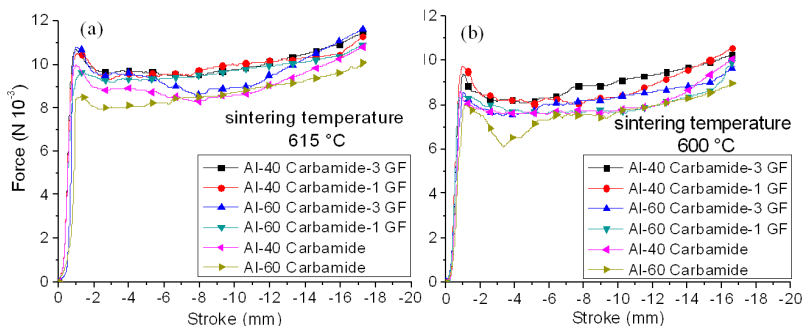

Fig. 6. Compression force-stroke curves of the foams: (a) liquid-state $\left(615^{\circ} \mathrm{C}\right)$, (b) solid-state $\left(600^{\circ} \mathrm{C}\right)$ sintering.

compressive strength and energy absorption capacity basically rely on two parameters: sintering temperature and the fractions of glass fiber. Compression properties were increased by decreasing the carbamide fraction and increasing glass fiber fraction.

\section{Conclusion}

Effects of glass fiber reinforcement on the Al-foams with different carbamide content processing, microstructure, compression and energy absorption properties were investigated. Based on the results, the following conclusions can be drawn. The compacting pressure must be set at $300 \mathrm{MPa}$ in order to retain the original shape of carbamides without any distortion. Liquid-state sintering should be implemented to obtain appropriate structural and mechanical properties. There was a positive effect on the total removing time of carbamide in using glass fiber reinforcement. Mechanical performance characteristics of produced foams using SDP technique was improved by glass fiber reinforcement. Also, it was found that the compressive properties and energy absorption behavior depend on the volume fraction of glass fiber and porosity fraction.

\section{References}

[1] A. Rabiei, A.T. O'Neill, Mater. Sci. Eng. A Struct. 404, 159 (2005).

[2] M. Malekjafarian, S.K. Sadnezhaad, Mater. Des. 42, 8 (2012).

[3] B. Matijasevic-Lux, J. Banhart, S. Fiechter, O. Goerke, N. Wanderka, Acta Mater. 54, 1887 (2006).

[4] F. Campana, D. Pillone, Mater. Sci. Eng. A Struct. 479, 58 (2008).

[5] B. Jiang, Z. Wang, Z. Naiqin, Scr. Mater. 56, 169 (2007).

[6] S. Esmaeelzadeh, A. Simchi, D. Lehmhus, Mater. Sci. Eng. A Struct. 424, 290 (2006).

[7] N. Michailidis, F. Stergioudi, A. Tsouknidas, E. Pavlidou, Mater. Sci. Eng. A Struct. 528, 1662 (2011).

[8] M. Alizadeh, M. Mirzaei-Aliabadi, Mater. Des. 35, 419 (2012).

[9] H. Bafti, A. Habibolahzadeh, Mater. Des. 31, 4122 (2010).

[10] B. Jiang, N.Q. Zhao, C.S. Shi, X.W. Du, J.J. Li, H.C. Man, Mater. Lett. 59, 3333 (2005).

[11] N. Bekoz, E. Oktay, J. Mater. Process. Tech. 212, 2109 (2012).

[12] A. Hassani, A. Habibolahzadeh, H. Bafti, Mater. Des. 40, 510 (2012).

[13] Y.Y. Zhao, D.X. Sun, Scr. Mater. 44, 105 (2001).

[14] H. Bafti, A. Habibolahzadeh, Mater. Des. 52, 404 (2013).

[15] H.I. Bakan, Scr. Mater. 55, 203 (2006). 